\title{
A comparison of two methods of data collection for modelling productivity of harvesters: manual time study and follow-up study using on-board-computer stem records
}

\author{
J. Brewer, B. Talbot, H. Belbo, P. Ackerman, S. Ackerman
}

Brewer J., Talbot B., Belbo H., Ackerman P., Ackerman S., 2018. A comparison of two methods of data collection for modelling productivity of harvesters: manual time study and follow-up study using on-board-computer stem records. Ann. For. Res. 61(1): 109-124.

Abstract. Productivity of a mechanized $P$. patula cut-to-length harvesting operation was estimated and modelled using two methods of data collection: manual time study and follow-up study using StanForD stem files. The objective of the study was to compare the productivity models derived using these two methods to test for equivalence. Manual time studies were completed on four different machines and their operators. Two Ponsse Bear harvesters fitted with $\mathrm{H} 8$ heads, and two Ponsse Beaver harvesters, fitted with H6 heads, were included. All machines were equipped with Ponsse Opti2 information system. All four operators had approximately 1 year of experience working with their respective machines. The four machines worked in separate four-tree-wide harvesting corridors, and they each harvested 200 trees. Individual tree diameter at breast height (DBH), and height measurements were made manually. Subsequently, data on the trees in each study were extracted from the StanForD stem reports from each of the harvesters. Cycle times in the stem reports were determined based on the difference between consecutive harvest timestamps. The two methods were compared in terms of their abilities to estimate equivalent measures for tree DBH, volume, and productivity. In all four cases, significant differences were found between the DBH and volume measures derived using the two methods. Subsequently, the volume measures from the manual methods were used as the basis for productivity calculations. Results of the productivity comparisons found no significant differences between the models developed from the two methods. These results suggest that equivalent productivity models can be developed in terms of time using either method, however volume discrepancies indicate a need to reconcile bark and volume functions with the high variability experienced in the country.

Keywords P. patula, cut-to-length harvesting, CTL harvesting, DBH comparison, stem files, estimating productivity

Authors. Julia Brewer, Pierre Ackerman - Department of Forestry and Wood Science, Stellenbosch University. Private Bag XI, Matieland. 7602. South Africa; Bruce Talbot, Helmer Belbo - Department of Forestry and Forest Re- 
sources, Norwegian Institute for Bioeconomy Research. Hoegskoleveien 7. Ås, Norway; Simon Ackerman - Institute for Commercial Forestry Research. PO Box 100281, Scottsville 3209, South Africa.

Manuscript received February 8, 2018; revised March 29, 2018; accepted April 2, 2018; online first April 13, 2018.

\section{Introduction}

As opposed to the forest operations in the northern hemisphere which have been mechanized since the early 1980's (Eriksson and Lindroos 2014), some of the larger forestry companies in South Africa are only now making a shift to mechanized cut-to-length (CTL) harvesting operations (Ackerman et al. 2017). Perceived related benefits as seen from the South African and an international perspective include increased productivity, improved wood quality and fibre utilisation, and improved health and safety conditions for forest workers (Jirousek et al. 2007, Cosola et al. 2016, Ackerman et al. 2017). However, increased use of machinery in harvesting practices, compared to traditional motor manual harvesting, increases fuel consumption, leading to high operational costs and increased $\mathrm{CO}_{2}$ emissions (Ackerman et al. 2017). Greater productivity has been found to optimize specific fuel consumption in harvesting operations (Spinelli et al. 2014) . Thus, the development and refinement of work productivity models for fully mechanized operations has been a common procedure in forest operations for decades (Visser \& Spinelli 2012; Eriksson \& Lindroos 2014, Labelle et al. 2016). In order to make improvements in operational efficiency of harvesting systems, it is important that productivity be well monitored and understood (Arlinger \& Moller 2007, Alam 2012, Labelle et al. 2016, Olivera et al. 2016,).

Numerous productivity studies have been documented in forest operations research literature (e.g. Kärhä et al. 2004, Jirousek et al. 2007, Nuutinen 2013, Alam et al. 2017;). The methods of acquiring productivity data used today can vary considerably and mainly depend on the precision of information required and the resources available (Eriksson \& Lindroos 2014). Traditionally, manual time studies are conducted in which productivity is assessed on the bases of stopwatches or other handheld data loggers to measure cycle and element times, with individual tree dimensions measured using DBH tapes, callipers, hypsometers and other equipment (Magagnotti et al. 2011, Olivera et al. 2016). Several studies have been completed where traditional time study methods have been used to develop adequate productivity models (e.g. Eliasson et al. 1999, Odhiambo 2010, Williams \& Ackerman 2016, Kulak et al. 2017). However depending on the study length, these techniques are often expensive, time consuming, and require skilled observers to minimize data collection errors (Nuutinen et al. 2008, Olivera et al. 2016, Spinelli et al. 2013). Additionally observer effects, such as the Hawthorne effect which reflects the tendency for the performance of individuals to change when they are being observed must be considered to minimize impact on machine operator performance (Sängstuvall 2010, Magagnotti \& Spinelli 2012, Erikson \& Lindroos 2014).

Another method of collecting data is by completing follow-up studies, where data which was recorded during an operation's normal activity is gathered and used to model and predict productivity (Magagnotti et al. 2017). With the advent of automated data collection on cut-tolength (CTL) machines, it has become possible for data to be collected using the machines' onboard computer (OBC) system and standards for production reports (StanForD) (Arlinger \& Moller 2007, Eriksson \& Lindroos 2014, Strandgard et al. 2013, Olivera et al. 2016). 
This method of automating data collection is potentially more time and cost efficient, and provides opportunities for gathering data that previously would have been difficult to acquire (Eriksson \& Lindroos 2014). However, notable limitations have been identified in previous studies using OBC data to model productivity (Eriksson \& Lindroos 2014). For example, Heinemann (2001) found that datasets from different machines contained a number of inaccuracies and inconsistencies making them difficult to utilize and compare. Without direct observation during the time of data collection there is a lack of ability to identify particular elements and delays within work cycles, as well as specific terrain characteristics that may have influenced cycle length (Olivera et al. 2016). This poses additional limitations to the use of OBC data for productivity modelling.

Various studies have used automatically recorded (OBC) data for productivity modelling (Olivera et al. 2016). However, few studies have tested or validated this method by comparing the machine derived productivity models to models developed using traditional time study methods. Strandgard et al. (2013) calculated and modelled productivity using StanForD stem (*.stm) files by using the difference between consecutive harvest time stamps to determine cycle length. According to Strandgard et al. (2013) when compared with productivity models produced from time study data on the same set of trees, and using consistent individual stem volume measures for the two datasets, no significant differences were found suggesting that productivity could be accurately modelled using data from StanForD stem files.

This study will explore further the relationship between the productivities produced using two methods of data collection: Time Study manual time study following the Standards for Time Studies for the South African Forest Industry (Ackerman et al. 2014) and Stem File - follow-up study using the machine archive data in the StanForD stem files. The study will also attempt to identify sources of potential deviations in parameters measured by the two methods. Additionally the study will assess the validity of using stem file data to calculate and model productivity. This will be done by comparing the tree dimensions (Diameter at Breast Height (DBH) and volume as well as the productivity models estimated using the two methods. More in depth, the study objectives were: (i) to calculate the productivity, and develop productivity models for CTL harvesters using data collected from two study methods: Time Study, and Stem File, (ii) to compare and develop a relationship between the Time Study productivity and the Stem File productivity, (iii) to assess whether statistically equivalent productivity models can be developed using two methods of data collection: Time Study and Stem File, (iv) to identify sources of potential deviation in parameters measured using two different study methods: Time Study and Stem File.

\section{Materials and methods}

\section{Study site}

Data collection took place in a clearfelling $P$. patula compartment, in the Highveld region of Mpumalanga, South Africa. This region is characterized as having a sub-tropical, seasonally arid climate, with hot wet summers and cool dry winters (Louw \& Scholes 2002). Annual rainfall is between $840 \mathrm{~mm}$ and $1670 \mathrm{~mm}$ with mean temperature ranging between $13.7^{\circ}$ C to $19.4^{\circ} \mathrm{C}$ (Louw \& Scholes 2002) with the minimum temperatures occurring during the winter months (May to August). The study took place in the month of July in which the recorded rainfall was $0.5 \mathrm{~mm}$.

The study took place in a single compartment throughout which the terrain, slope, and tree characteristics were consistent. The study compartment had an upper left GPS coordinates of $26.310^{\circ} \mathrm{S}$ and $30.699^{\circ} \mathrm{E}$ and lower right GPS coordinates of $26.315^{\circ} \mathrm{S}$ and $30.709^{\circ}$ E. The compartment was characterized as having a relatively low level of ground 
roughness, good ground strength and a slope of $<15 \%$ (0\% to $14 \%$ ) according to the National Terrain Classification for Forestry (Erasmus 1994). The stand age of the compartment was 22 years at the time of felling, stand density was 380 stems $^{\cdot h h^{-1}}$, and mean stem volume was $1.05 \mathrm{~m}^{3}$.

\section{Study layout}

The studied site was demarcated into four individual, four tree wide, harvesting corridors (referred to as Swath I, Swath II, Swath III, and Swath IV) each containing two-hundred trees, with the exception of Swath IV which contained 197 trees (Figure 1). Swath width was governed by normal production orientated operational procedures of the harvesters; felling in a four row wide path through the compartment. As displayed in Figure 1, each swath had an edge row of trees (row 6), adjacent to an access row (row 7), which had been felled previously at an age of 8 years, during routine thinnings. Consequently (Table 1), all swaths contained a similar number of edge trees, which were potentially larger in size due to having greater resource allocation (Ackerman et al. 2013, Ackerman et al. 2016).

Each of the four harvesters and their respective operators were randomly assigned to the four swaths, each of which constituted a separate study (Table 1). Two models of Ponsse harvesters were used in the studies: the larger 8-wheeled, $260 \mathrm{~kW}$ Bear, a typical final felling machine, and the smaller, 6-wheeled, 129 kW Beaver, a thinning machine (Table 1). All harvesters were equipped with Ponsse Opti2 information system (Ponsse Oyj 2017). Each harvester's head and OBC was calibrated for diameter and length immediately before commencing the study. All four harvesters were the same age (c. 18 months; Table 1), and all machine operators had been through the same extended training program on a Ponsse simulator, and consequently had approximately one year of operational experience working with their harvester.

\section{Data Collection}

Volume measurements (manual)

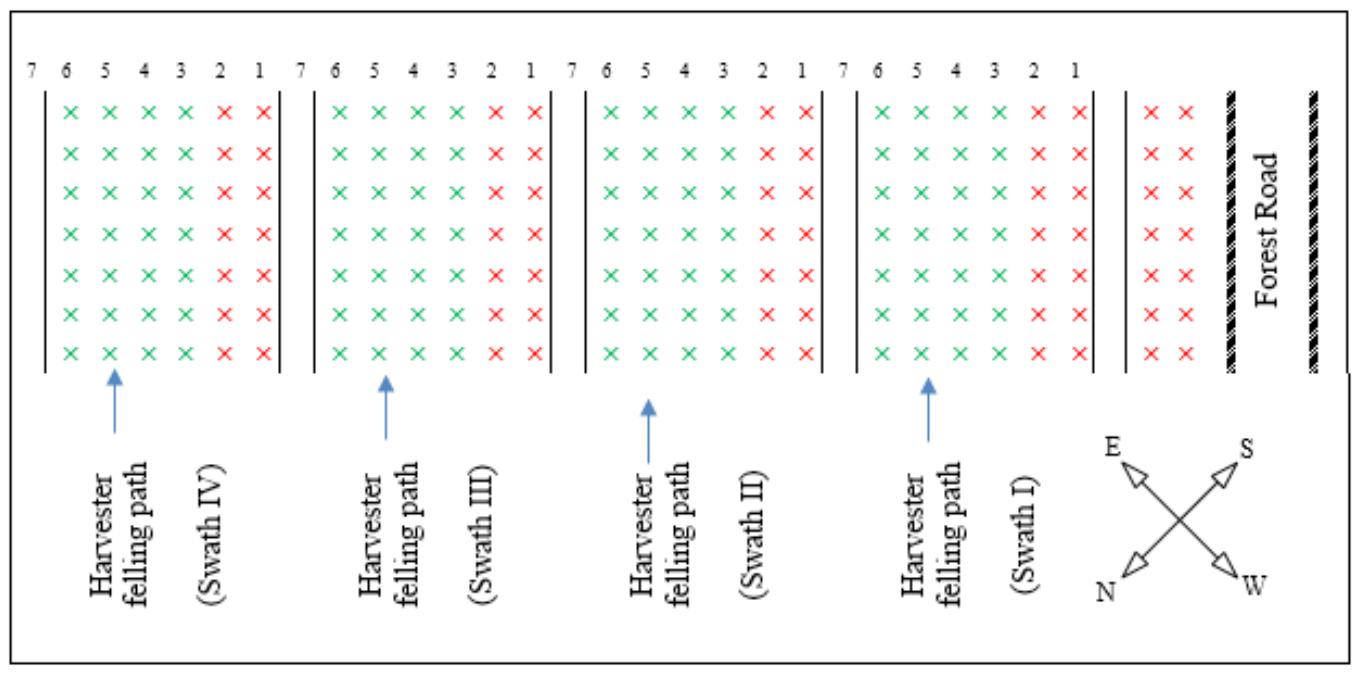

Figure 1 Diagram of study layout indicating an open $7^{\text {th }}$ row. Green "x's" indicate trees felled during the study. Red " $x$ 's" indicate trees not felled during the study. The $7^{\text {th }}$ rows are previously felled access routes. 
Table 1 Tree and machine specifications for the studied swaths

\begin{tabular}{lllll}
\hline Tree Specifications & Swath I & Swath II & Swath III & Swath IV \\
\hline Number of trees & 200 & 200 & 200 & 197 \\
Number of edge trees & 56 & 51 & 57 & 61 \\
Average volume $\left(\mathrm{m}^{3}\right)$ & 1.12 & 1.22 & 1.12 & 1.33 \\
Machine Specifications & Swath I & Swath II & Swath III & Swath IV \\
Machine make and model & Ponsse Bear & Ponsse Beaver & Ponsse Bear & Ponsse Beaver \\
Age (machine hours) & 2053 & 2285 & 2070 & 2150 \\
Engine power $(\mathrm{kW})$ & 260 & 129 & 260 & 129 \\
Harvesting head & H8 & H6 & H8 & H6 \\
\hline
\end{tabular}

Prior to harvest, DBH (overbark) were recorded for all trees in swaths I to IV. DBH measurements were made using a diameter tape with a precision of $0.1 \mathrm{~cm}$. The heights of 40 trees per swath (every $5^{\text {th }}$ tree) were measured using a Haglöf Vertex hypsometer with a precision of $0.1 \mathrm{~m}$. A distinctive number was marked on every tree in the study to assist in tree identification during harvesting to allow for pairing of tree dimensions with individual tree time study data.

To predict the heights of the remaining trees in the study, a classic DBH-to-height curve was used.

Using the measured and predicted DBHheight pairs, the Schumacher \& Hall function (Equation 1) parametrized locally for P. patula (Bredenkamp \& Upfold 2012) was used in calculating tree volumes:

$\ln (V)=b_{0}+b_{1} \ln (d b h+f)+b_{2} \ln (H)$

where: $\ln$ - natural logarithm to the base e, $V$ - stem volume ( $\mathrm{m}^{3}$, under-bark), dbh - breast height diameter (cm, over-bark), f - over-bark to under-bark conversion factor for $P$. patula, $H$ - tree height (m), $b_{0}=-13.469, b_{1}=1.440, \mathrm{f}$ $=8, b_{2}=1.325$.

\section{Time Study}

Time study data was recorded on an Android Application (Time Study App), for each of the harvesters as they worked through their allocated swaths. The application was developed for element level time studies by the University of Stellenbosch Department of Forest and Wood Science following the Standards for Time Studies for the South African Forest Industry (Ackerman et al. 2014). The Time Study App was programmed to record all time in minutes at a "milliminute" (i.e. $1000^{-1} \mathrm{~min}$, i.e. 0.06 second) resolution, as prescribed in Kanawaty (1992). The time study elements for mechanized harvesters are presented in Table 2 (Ackerman et al. 2014). As the objective of this study was not concerned with the productivity of individual elements, the harvester cycle elements were simplified and only fell/process (combined into a single element), travel and delay times were recorded (Table 2).

\section{Stem Files}

Tree data were extracted from stem reports (.stm) from each of the harvesters (StanForD team 2007, 2012). Prior to harvesting, machine operators logged into a new cut object on the harvester's computer to identify each study on the machine's dataset. Studies were identified from the StanForD stem files based on the date, start time, machine ID, and operator listed in the file. $\mathrm{R}$ (R Core Team) was used to set up scripts for extracting and organizing data from the stem reports allowing for extraction of parameters found relevant to productivity.

\section{Data Analysis}

Matching Time Study data with Stem File data 
Table 2 Time study elements for mechanized harvester (Ackerman et al. 2014)

\begin{tabular}{ll}
\hline Element & \multicolumn{1}{c}{ Description } \\
\hline Travel & $\begin{array}{l}\text { Begins when the machine starts to move to a new position and ends when the boom starts to } \\
\text { swing towards the next tree to be felled. } \\
\text { Begins when the head is resting in position on the tree and ends when the tree starts to fall } \\
\text { and ends once the tip of the tree is discarded and either the harvester's tracks begin to move } \\
\text { or the head is gripped in the resting position on the next tree. } \\
\text { Fegins when the boom starts to swing towards a tree to be felled and ends with the head } \\
\text { resting in position on the tree for the felling cut to commence. }\end{array}$ \\
Boom-out & $\begin{array}{l}\text { Begins when the head is resting in position on the tree and ends when the tree starts to fall. } \\
\text { Felling }\end{array}$ \\
Boom-in & $\begin{array}{l}\text { Begins when the tree is falling and the boom starts to swing towards and stops in front of the } \\
\text { base of the machine. The element ends when the feed rollers start to turn in the processing } \\
\text { area at the machine front }\end{array}$ \\
Processing & $\begin{array}{l}\text { Begins when the feed rollers start to turn and ends when the harvester begins to move to a } \\
\text { new position (delimbing, and cross-cutting) } \\
\text { Clearing ground; moving tops, branches and slash; stacking logs; refuel time (in shift); repair } \\
\text { time (in shift); maintenance time (in shift); other delays (planning, rest...) }\end{array}$ \\
Delays &
\end{tabular}

For each swath, the following study parameters were named and extracted from the StanForD stem records: "stem number" (reflects the cycle number), "harvest timestamp" (gives the exact time in h:m:s format at which processing of an individual tree was completed), "seconds per tree" (difference between consecutive time stamps), "DBHcm" (over-bark diameter at breast height measurement for a particular tree), "stemVolM3sob" (total overbark volume estimate for a particular tree).

The Time Study App creates and outputs a single timestamp (h:m:s) when the study is initiated. Times for successive cycles were added to this in generating individual timestamps for each cycle in the Time Study dataset, and these timestamps were used to align the manually recorded dataset to the .stm file based dataset. Each stem number from the Stem File dataset was then matched with the corresponding cycle number in the Time Study dataset.

\section{"Cleaning" the data}

Time study protocol, as outlined in Ackerman et al. (2014), suggests that all travel element times be summed and divided equally among all trees in the dataset. Additionally, protocol suggests that if working in productive machine 114 hours (PMH), delay times should be removed completely from each cycle in which the delays occur (Ackerman et al. 2014; Björheden and Thompson 1995). However, only the total cycle time can be interpreted from StanForD stem files since individual elements and delays are not recorded. Thus for the Stem File dataset, travel and delay times could not be separated from the elements relevant to the study. In order to reduce differences between the two datasets allowing for proper matching of the Stem File cycles with the Time Study cycles, travel times in the Time Study dataset were left in the cycles in which machine re-positioning occurred. Similarly, delays were left in their corresponding cycles for this part of the analysis.

Additional "cleaning" of the datasets took place in order to remove delays and anomalies in the data. Cycles which contained one or more of the following characteristics were removed from both the Time Study and Stem File datasets: (i) cycles containing delays, regardless of duration, as recorded in the Time Study dataset, (ii) cycles containing travel time, as recorded in the Time Study dataset, which is more than one standard deviation greater than the mean move time (this was considered a delay), (iii) cycles that were not 
linked to a tree identification number during the time study, resulting in an inability to link with manually recorded tree $\mathrm{DBH}$ and Volume dimensions.

The last point was often a result of poor visibility during the time study due to the need to stand at a safe distance from the harvester while completing the study. As a result of data "cleaning", the number of cycles used for further data analysis and modelling was reduced. The modelled sample sizes were 165 for Swath I, 158 for Swath II, 172 for Swath 3, and 125 for Swath 4.

\section{Tree parameters (DBH and volume)}

The procedures followed to measure individual tree DBH and volume differ when calculated using manual methods (Equation 1) and when calculated by the harvester head (stored in stem files). In this study the DBH is represented as the diameter taken at $110 \mathrm{~cm}$ (set by the company management) from the base of the cut log. The harvester then approximates tree volumes by summing the volumes of the merchantable logs. This could potentially result in an underestimate compared to the tree volumes calculated using Equation 1 depending on the height at which the tree was felled, and the amount of unprocessed waste material, something not expressed in the manual volume calculations.

The tree DBH and volume measures were compared between the two methods and a $t$-test was performed to determine if there were any significant differences between the means. In the case that significant differences in tree dimensions were found between the two methods, the individual tree volumes calculated using the manual method (Schumacher-hall function) would be used to represent volume for both datasets. This would be done to keep the tree volume estimates consistent and to isolate differences in time between the two study methods.

\section{Productivity}

Using the recorded cycle times and individual tree volumes, the productivity was calculated for each individual cycle for both the Time Study and Stem File datasets. Productivity is estimated in units of $\mathrm{m}^{3} \mathrm{PMH}^{-1}$.

For the productivity data from each swath, a repeated measures analysis of variance (ANOVA) was performed to determine if the predicted productivities differed depending on study method (Time Study or Stem File). To account for non-normality in the data, the ANOVA was subsequently followed by a post hoc analysis and a Wilcoxon Matched Pairs test was performed to verify the results. The productivities achieved using the two different methods were compared and a relationship between them was determined using a linear regression.

\section{Modelling}

For each swath, two models were created: one was created by plotting the Time Study productivity on the y-axis with tree volume $\left(\mathrm{m}^{3}\right)$ on the $\mathrm{x}$-axis, and for the other the Stem File productivity was plotted on the y-axis against tree volume $\left(\mathrm{m}^{3}\right)$ on the $\mathrm{x}$-axis. Both models had a linear fit as described by Equation 2:

$P=\left(B_{0}\right) V+B_{1}$

where: $P$ - productivity - time study or stem file $\left(\mathrm{m}^{3} \mathrm{PMH}^{-1}\right), V$ - tree volume $\left(\mathrm{m}^{3}\right), B_{0}$ slope of the regression, $B_{1}$ - Intercept.

For each swath, the Time Study productivity model and the Stem File productivity model were subsequently tested against each other for significant differences using a univariate test of significance.

\section{Results}

Comparison of manual versus harvester estimates for tree volume and DBH 
Harvester measured DBH was generally lower than manually measured DBH although in some cases it was considerably over estimated (Figure 2A). For smaller trees (volume $<0.8 \mathrm{~m}^{3}$ ), the harvester measured volume was generally greater than manually measured volume, and for larger trees (volume $>0.9 \mathrm{~m}^{3}$ ), the harvester measured volume was generally lower than the manually measured volume (Figure 2B). These effects are also shown in the spread of the measured values for $\mathrm{DBH}$ and volume shown in Figure 3A and Figure 3B respectively.

The results of the $t$-test comparing the manually measured DBH (and tree volume) to the harvester measured $\mathrm{DBH}$ (and tree volume) show that in all four cases, the two DBH (tree volumes) measures differed significantly (Table 3). As a result, the individual tree volume estimates calculated using the Schumacher-hall function and the manually measured DBHs were used to represent individual tree volumes in the productivity calculations for both datasets (Time Study and Stem File).

\section{Productivity comparison}

Table 4 shows the Time Study and Stem File productivity results for each swath. Due to non-normality of the data, a Bootstrap analysis
(Figure 3C) and a Wilcoxon Matched Pairs test (Table 5) were completed to determine if the mean productivities differed significantly between the Stem File and Time Study datasets for Swaths I-IV.

The Stem File productivity was plotted against Time Study productivity using the pooled data from Swaths I - IV (Figure 4), and the relationship described by the following generalized linear regression model (Equation 3):

Stem $=0.8785(T S)+9.9161$

where: stem - Stem File productivity $\left(\mathrm{m}^{3} \mathrm{PMH}^{-}\right.$ $\left.{ }^{1}\right)$, TS - Time Study productivity $\left(\mathrm{m}^{3} \mathrm{PMH}^{-1}\right)$, with: $r=0.93, R^{2}=0.86$.

\section{Model comparison}

The linear model (Equation 2) parameters for predicting productivities as a function of tree volume for the Stem File dataset and the Time Study dataset are displayed in Table 6. Figure 5 displays the data spreads from which the linear models were generated for swaths I, II, III, and IV.

A GLM univariate analysis was performed to test for significant differences between the Stem File productivity model and the Time

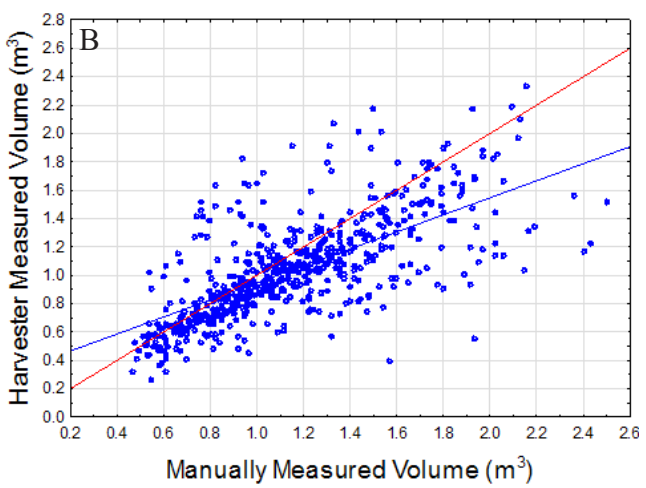

Figure 2 Comparison plot of manually measured DBH (A) and volume (B), versus harvester measured DBH (A) and volume (B). The plot uses the pooled data from swaths I, II, III, and IV. The blue line shows $\mathrm{y}=\mathrm{x}$, red line shows the relationship from the data. 

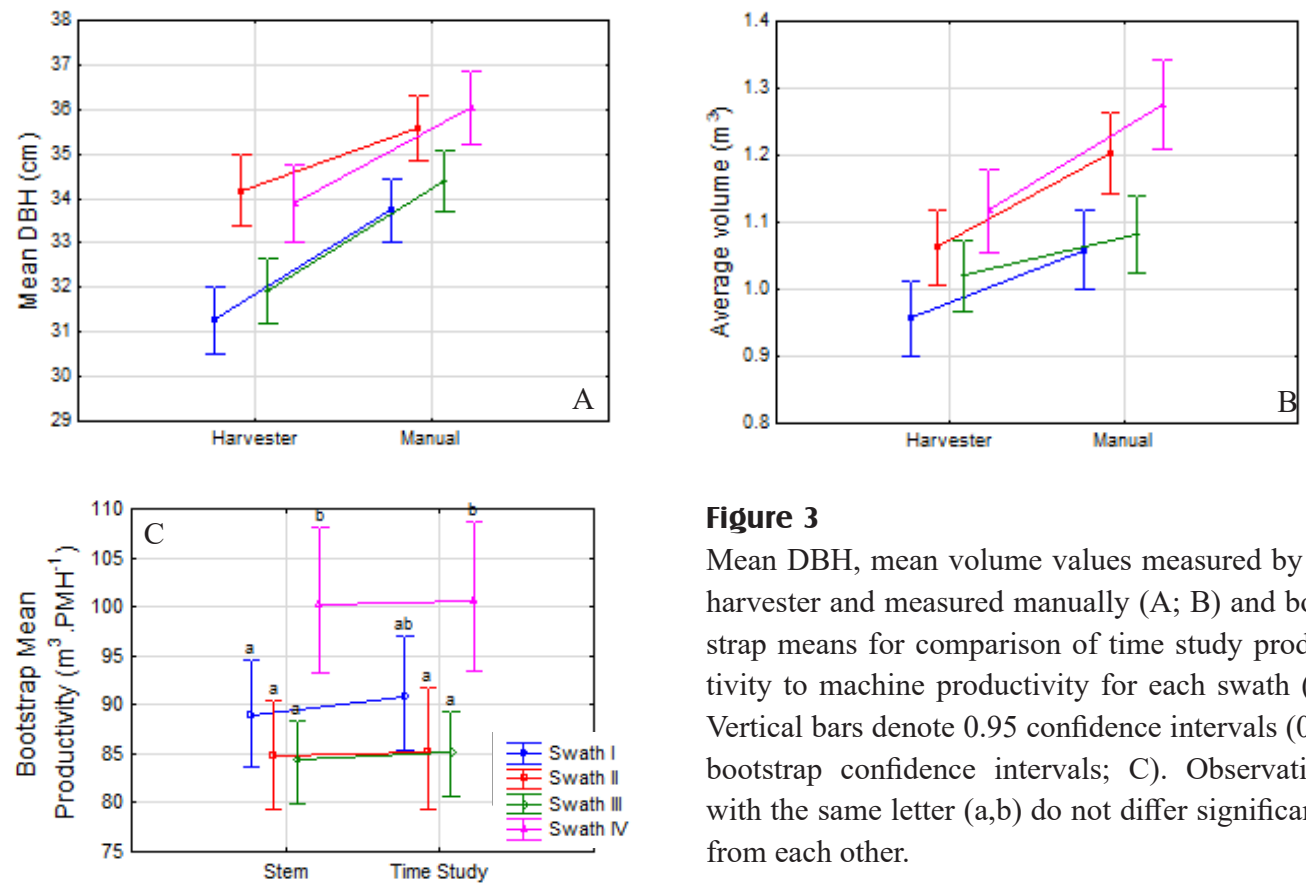

\section{Figure 3}

Mean DBH, mean volume values measured by the harvester and measured manually $(\mathrm{A} ; \mathrm{B})$ and bootstrap means for comparison of time study productivity to machine productivity for each swath (C). Vertical bars denote 0.95 confidence intervals $(0.95$ bootstrap confidence intervals; C). Observations with the same letter $(a, b)$ do not differ significantly from each other.

Table 3 Individual swath $t$-test (alpha $=0.05$ ) results for comparison of manually measured DBH and volume to harvester measured DBH and volume.

\begin{tabular}{ccccccc}
\hline \multicolumn{7}{c}{ DBH } \\
\hline Swath & $\mathrm{N}$ & Mean (manual) & Mean (harvester) & $\mathrm{T}$ - value & $\mathrm{df}$ & $\mathrm{p}$ \\
\hline 1 & 165 & 33.90 & 31.10 & 5.29 & 328 & $0.00^{* *}$ \\
2 & 158 & 35.74 & 34.01 & 2.76 & 314 & $0.01^{* *}$ \\
3 & 173 & 34.40 & 32.20 & 4.08 & 344 & $0.00^{* *}$ \\
4 & 125 & 36.01 & 33.81 & 3.47 & 248 & $0.00^{* *}$ \\
\hline \multicolumn{7}{c}{ Volume } \\
\hline Swath & $\mathrm{N}$ & Mean (manual) & Mean (harvester) & $\mathrm{T}-$ value & $\mathrm{df}$ & $\mathrm{p}$ \\
\hline 1 & 165 & 1.06 & 0.96 & 2.57 & 328 & $0.01^{*}$ \\
2 & 158 & 1.20 & 1.06 & 3.04 & 314 & $0.00^{* *}$ \\
3 & 173 & 1.08 & 1.00 & 2.31 & 344 & $0.02^{*}$ \\
4 & 125 & 1.28 & 1.12 & 3.05 & 248 & $0.00^{* *}$ \\
\hline
\end{tabular}

Study productivity model for each swath. The results of the GLM univariate analyses can be interpreted by analysing the $p$-value (knowing alpha to be $=0.05$ ) which can be taken as an indicator for statistical significance of differences (Table 7).

\section{Discussion}

Figure 4 shows the general relationship between the Time study productivity and the Stem File productivity. A trend between the productivities derived from these two methods can be observed by comparing the blue line $(y=x)$ to the red line which shows the trend 
Table 4 Productivity $\left(\mathrm{m}^{3} \mathrm{PMH}^{-1}\right)$ summary statistics by swath.

\begin{tabular}{lllllll}
\hline Swath & Method & $\mathrm{N}$ & Mean & Standard deviation & $10^{\text {th }}$ percentile & $90^{\text {th }}$ percentile \\
\hline \multirow{4}{*}{1} & Time study & 165 & 91.12 & 31.53 & 56.04 & 128.99 \\
& Stem file & 165 & 89.11 & 27.95 & 57.61 & 124.00 \\
2 & Time study & 158 & 85.17 & 30.62 & 52.43 & 115.36 \\
& Stem file & 158 & 84.64 & 29.85 & 54.82 & 110.84 \\
3 & Time study & 173 & 85.10 & 23.14 & 53.94 & 111.07 \\
& Stem file & 173 & 84.31 & 23.40 & 55.51 & 113.34 \\
4 & Time study & 125 & 100.79 & 34.75 & 60.79 & 134.77 \\
\hline
\end{tabular}

Table 5 Results of Wilcoxon Matched Pairs Test (alpha = 0.05) comparing the Time Study (TS) productivity $\left(\mathrm{m}^{3} \mathrm{PMH}^{-1}\right)$ and Stem File productivity $\left(\mathrm{m}^{3} \mathrm{PMH}^{-1}\right)$ for each swath.

\begin{tabular}{lllll}
\hline Swath & $\mathrm{N}$ & $\mathrm{T}$ & $\mathrm{Z}$ & $P$-value \\
\hline 1 & 165 & 5818 & 1.675 & 0.094 \\
2 & 157 & 5940 & 0.458 & 0.647 \\
3 & 173 & 7393 & 0.201 & 0.841 \\
4 & 125 & 3600 & 0.832 & 0.406 \\
\hline
\end{tabular}

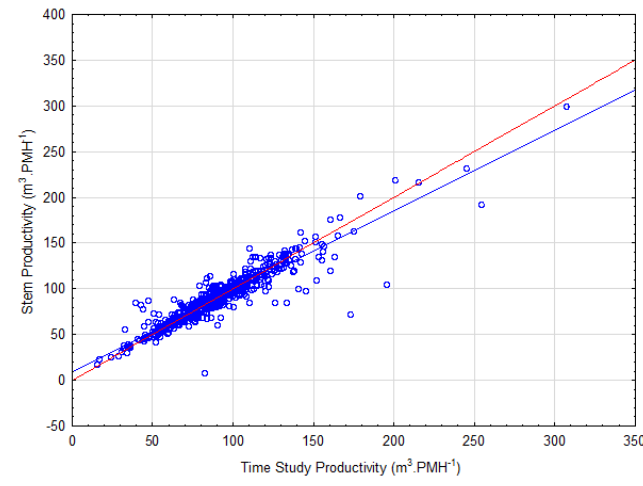

Figure 4 Plot of Stem productivity against Time Study productivity using the pooled data from Swaths I, II, III, and IV. The red line shows $\mathrm{y}=\mathrm{x}$, blue line shows the relationship from the data.

from the data. If the productivities predicted from the two methods were exactly the same, the red line would follow the trend described by the blue line. The trend shows that at the lower end of the productivities achieved in this study (below approx. $60 \mathrm{~m}^{3} \mathrm{PMH}^{-1}$ ), the Stem File productivity measures provide a higher estimate compared to the Time Study productivity measures. At the higher productivities 118 achieved in this study (above approximately $80 \mathrm{~m}^{3} \mathrm{PMH}^{-1}$ ) the Stem File productivity measures provide a lower estimate compared to the Time Study productivity measures. The relationship between the Time Study productivity and the Stem File productivity (Equation 3) was based on the data from four separate harvesters and can be generally applied if working within a similar range of productivities.

The mean productivities measured from the Time Study and Stem Files were $91.12 \mathrm{~m}^{3}$ $\mathrm{PMH}^{-1}$ and $89.11 \mathrm{~m}^{3} \mathrm{PMH}^{-1}$ respectively for Swath I, $85.17 \mathrm{~m}^{3} \mathrm{PMH}^{-1}$ and $84.64 \mathrm{~m}^{3} \mathrm{PMH}^{-}$ ${ }^{1}$ respectively for Swath II, $85.10 \mathrm{~m}^{3} \cdot \mathrm{PMH}^{-1}$ and $84.30 \mathrm{~m}^{3} \mathrm{PMH}^{-1}$ respectively for Swath III, and $100.79 \mathrm{~m}^{3} \mathrm{PMH}^{-1}$ and $100.21 \mathrm{~m}^{3} \mathrm{PMH}^{-}$ ${ }^{1}$ respectively for Swath IV. The productivity achieved in Swath IV was measured to be the highest when using both Time Study and Stem File methods, despite the use of the smaller, lower kilowatt harvester model (Beaver). In addition to operator influence, this can most likely be attributed to the harvester in Swath IV working with the highest average tree volumes out of any of the swaths (Table 1) which has a strong influence on productivity (Kärhä 
Table 6 Model parameters for predicting productivity as a function of tree volume

\begin{tabular}{llllll}
\hline Swath & Method & Modelled sample size & $\mathrm{B}_{0}$ & $\mathrm{~B}_{1}$ & $\mathrm{R}^{2}$ \\
\hline \multirow{2}{*}{1} & Time Study & 165 & 37.06 & 51.10 & 0.37 \\
& Stem File & 165 & 35.57 & 50.61 & 0.47 \\
2 & Time Study & 158 & 43.89 & 34.29 & 0.21 \\
& Stem File & 158 & 40.34 & 36.79 & 0.25 \\
3 & Time Study & 173 & 37.87 & 43.69 & 0.39 \\
4 & Stem File & 173 & 39.51 & 41.44 & 0.34 \\
& Time Study & 125 & 58.03 & 33.51 & 0.18 \\
& Stem File & 125 & 57.64 & 33.36 & 0.20 \\
\hline
\end{tabular}

Table 7 GLM univariate analysis results testing for difference $($ alpha $=0.05)$ between the Stem File productivity model and the Time Study productivity model in Swaths I, II, III, and IV.

\begin{tabular}{lllll}
\hline Swath & Sum of Squares & df & F & $p$ \\
\hline 1 & 33.6 & 1 & 0.64 & 0.42 \\
2 & 22.4 & 1 & 0.03 & 0.86 \\
3 & 54.5 & 1 & 0.16 & 0.69 \\
4 & 20.8 & 1 & 0.02 & 0.88 \\
\hline
\end{tabular}
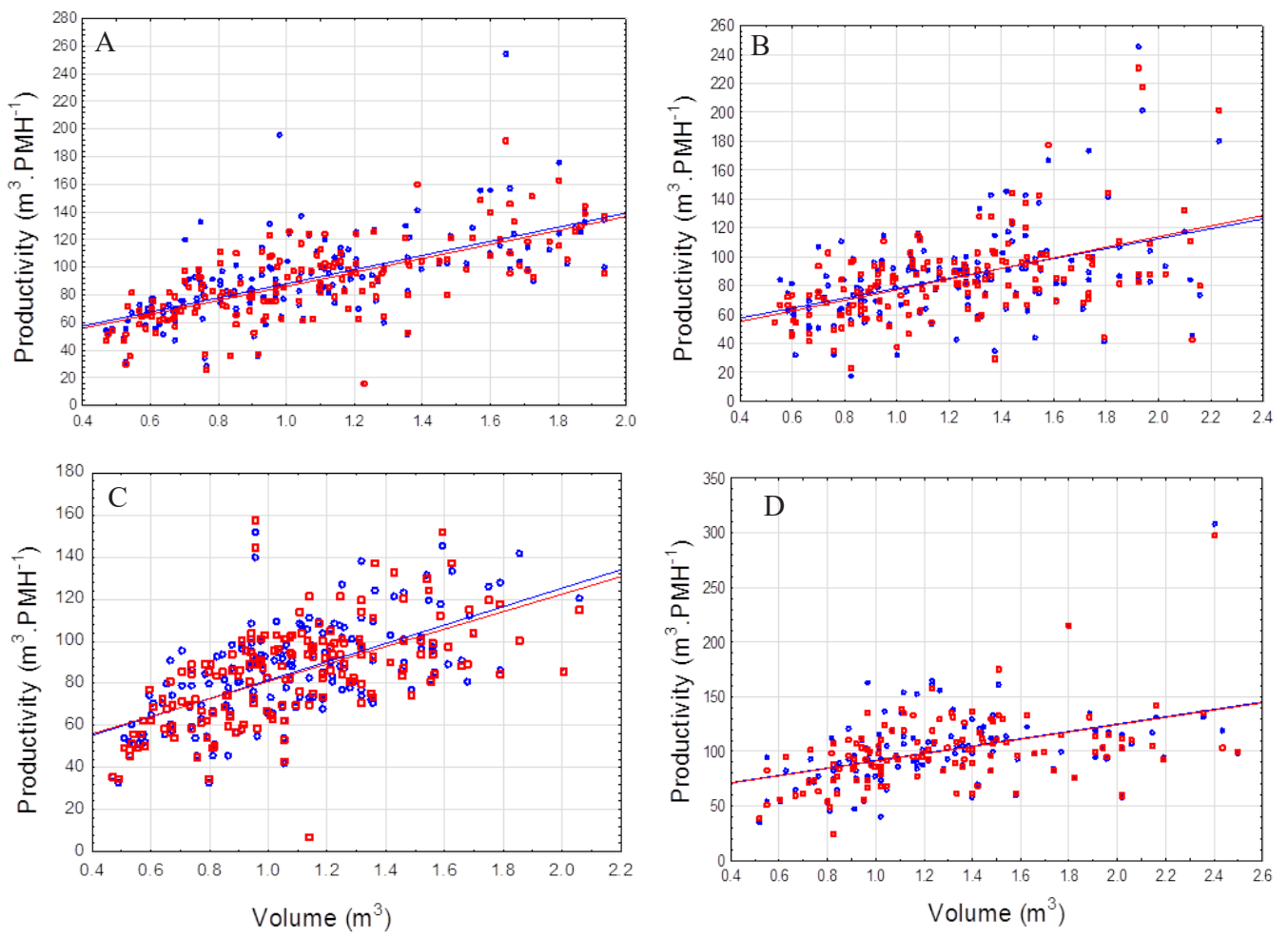

Figure 5 Scatterplot of Time Study (blue) and Stem File (red) productivity $\left(\mathrm{m}^{3} \mathrm{PMH}^{-1}\right)$ versus tree volume $\left(\mathrm{m}^{3}\right)$ for a) swath I; b) Swath II; c) Swath III; d) Swath IV. 
et al. 2004, Alam et al. 2012, Ramantswana et al. 2012, Visser \& Spinelli 2012).

The bootstrap means in Figure 3C, show that there were no significant differences between the Time Study and Stem File productivities for any swath. This effect was verified by the results of the Wilcoxon Matched Pairs Test (Table 5) which also shows no significant differences in any of the studied swaths. Similarly, in all four studied swaths, there were no significant differences found between the harvester productivity models developed from the two methods: Time Study and Stem Files. This result is consistent with findings in Strandgard et al. (2013), and verifies that productivity models derived using harvest timestamps in the StanForD stem files can be considered equivalent to productivity models developed using traditional time study methods. However, it should be noted that in both this study and Strandgard et al. (2013), this was true only when using the same set of measures for stem volume for both methods. In all four swaths, the $\mathrm{DBH}$ values measured by the harvester were lower than the DBHs that were manually measured using a DBH tape (Figure 2A; Figure 3A). Depending on the swath, manual measurement resulted in DBHs that were approximately $4 \%$ to $7 \%$ higher than the DBHs recorded in the stem files. This difference was found to be significant in all cases, using the four different harvesters (Table 3 ).

The manually measured values for $\mathrm{DBH}$ are hypothesized to be more accurate than the values measured by the harvester. This assumption is made for three reasons. First there is the knowledge of tree cross sections being potentially elliptical in shape (not precisely circular). Due to this, using a DBH tape which estimates an average diameter based on the log circumference, is assumed to be more accurate than the machine's grip (caliper) which only measures the diameter at one point on the stem. Another factor is that $P$. patula has thick corky bark at the point where $\mathrm{DBH}$ is measured, thus there is potential that the harvester grips the log with such a force that the bark of the log could become slightly compressed which might result in an underestimated diameter value. A final factor is associated with the machine operating system's method for predicting DBH. The Ponsse Opti information system measures stem diameters during processing by gripping and guiding the harvested log through a measuring wheel (or sprocket) lodged within the harvester's head. Using this method, the harvester records the stem diameter at the base and then at every 10 cm interval (Koskela et al. 2011). In this study the $\mathrm{DBH}$ was programmed to be the $12^{\text {th }}$ stem diameter recorded, i.e. the machine registered DBH was measured at $110 \mathrm{~cm}$ height from the base of the butt log. This method assumes that the operator will consistently fell the trees $20 \mathrm{~cm}$ above ground level and thus the DBH measurement is recorded at a height of 130 $\mathrm{cm}$ total from ground level. However, since the actual height from which the operator fells the tree is unknown and can vary from tree to tree depending on site conditions and operator attitude or level of experience, the height at which the DBH was recorded by the harvester is also variable. In the case of this study, it is possible that the trees were felled higher than $20 \mathrm{~cm}$ from the ground, resulting in a DBH measure which is lower than what was manually measured at the consistent height of $130 \mathrm{~cm}$. There are a few factors which could have caused or contributed to this observed effect. The most prominent factor being that an over all operator approach of working quickly to complete the task was observed in the four trials, which might have been a result of the Hawthorne effect. This may have resulted in operators not paying adeqaute attention to positioning the head prior to felling. This is reinforced from results of a study by Ackerman \& Pulkki (2012) which found that stems were cut an average of $7 \mathrm{~cm}$ above the recommended felling height of $20 \mathrm{~cm}$ (Brink et al. 2000). That study included both mechanized and motor-manual felling (Ackerman \& Pulkki 2012). 
The current study unfortunately did not do an assessment of stump heights so the view that stumps were cut higher than required remains speculation at this point in time.

The volume measurements made by the harvester were also significantly lower than the measurements made using manual methods in all four swaths (Figure 3B; Table 3). Thus, as with the $\mathrm{DBH}$ measurements the machine calculated volumes are not equivalent to those calculated using the Schumacher-hall function. This difference is additionally in line with the expectations outlined in the methods section and is likely due to differences between the methods carried out manually and by the harvester when measuring $\mathrm{DBH}$ and calculating volume. While the volume calculations using the Schumacher-hall function allows an approximation of the merchantable volume of each individual tree from the base of the tree to a $75 \mathrm{~mm}$ top diameter, tree volumes recorded in the stem files only reflect a sum of the commercial volume of the timber actually produced. Each log contains a given amount of waste material. This will vary between trees and based on operator approach to bucking (e.g., waste due to forks removal and/ or branch whorls which are out of specification and which are not processed by the harvester head).

Therefore, the manual method of estimating volume could result in an overestimate compared to the volume estimated by the harvester. This factor may have contributed to the observed discrepancy in volume estimations between the two methods. Since individual tree volume is known to have a significant effect on productivity (Kärhä et al. 2004, Ramantswana et al. 2012, Visser \& Spinelli 2012, Erikson \& Lindroos 2014), the productivity derived using the tree volumes recorded in the stem files can also be expected to be an underestimate compared to what is achieved using verified manual methods. This result suggests that although equivalent productivity models can be developed using either the Time Study or Stem file methods in terms of time, these methods would not measure productivity equivalently if the two different methods of estimating volume were applied. For this study, the manually measured volumes before the actual harvesting of the trees, were applied to both the Time Study and Stem File data set. Future research might want to consider exploring which of these methods for determining individual tree volumes is more accurate by comparing these two volumes measured using other verified methods. There is a possibility of additionally using remote sensing technology to determine tree volumes, however this could potentially be less accurate than using the methods used in this study; more research should be done to test this assumption. Concluding this issue might contribute to more accurate modelling of mechanized CTL harvester productivity in the future.

In addition to the inconsistency in estimates of DBH and volume, there are a few other potential shortcomings to using the Stem File method for predicting productivity as highlighted by this study and outlined in literature records. As mentioned in the methods section, the individual elements and delays within a cycle cannot be separated in the machine data, as their sequence within a cycle cannot be determined (Palander et al. 2013, Olivera et al. 2016). This limits the ability to determine bottleneck elements within the cycle to focus attention to individual cycle components being researched. Additionally, this does not allow for travel elements to be summed over the entire study, resulting in particular cycle durations being penalized and potentially skewed. The inability to identify delays and remove these from the dataset when using stem files can also potentially lead to productivity measures which are less accurate or skewed. It is important to note that these issues have only been identified in the use of StandForD Stem files for estimating productivity. Machine Manufacturer's own reporting software (e.g. Opti, Maxifleet and Timbermatic) do comple- 
ment StanForD with additional CAN-bus data (Nuutinen 2013). However, even when utilizing the CAN-bus data, the sequence in which elements are carried out still cannot be identified (Nuutinen 2013, Palander et al. 2013).

Another potential shortcoming is that the time recorded in the stem files is measured and recorded to the nearest second. The resolution of the Time Study App is 0.06 seconds $\left(1000^{-1}\right.$ minutes), allowing for more precise measures of cycle times to be recorded and, in turn, more accurate estimations of productivity (Kanawaty et al. 1992). Additionally, data describing weather and site conditions, as well as tree form, are difficult or even impossible to record without direct observation. The effect of these variables on cycle productivity are therefore difficult to include in studies solely based on machine reports (Strandgard et al. 2013; Olivera et al. 2016). This implies that despite the benefits possibly available using OBC systems, certain studies where observational or element level detail is required, for example shift level studies, will rely on alternative methods of monitoring the operation in order to define the detail required.

The use of video cameras or other sensors have been found to work effectively in supplementing time study data. Nurminen et al. (2006) supplemented the OBC derived data with analysis of video recordings, as did Labelle et al. (2016), who used the video to analyse tree shape in determining its effect on productivity. Contreras et al. (2017) installed a multiple camera surveillance system to a cable skidder, allowing them to record over longer time periods, and investigate any deviations from normal operations in detail. For longer term studies, where objectives are concerned with global productivity trends, automated systems generally provide sufficiently detailed data (Purfürst 2010, Purfürst \& Lindroos 2011, Eriksson \& Lindroos 2014).

Despite the shortcomings, various benefits to using the Stem File method for productivity modelling have also been identified by liter- ature and highlighted in this study. The most evident benefit is that utilising automatically collected data from stem files offers a much more efficient method of productivity modelling in terms of time and economics (Nuutinen 2013, Strandgard et al. 2013, Olivera et al. 2016). Another advantage to using stem files, is that they collect location coordinates which can be paired with GPS and Lidar to assist in investigating the effects of terrain and slope on productivity. Use of stem file data may also allow for the potential to collect and analyze much larger datasets through the use of better adapted statistical methods allowing for more practical, and general models to be developed (Olivera et al. 2016). Incorporating these large datasets may also help to mitigate some of the operational anomalies and delays due to particular site and stand conditions. Future studies could explore whether the effect of site and stand characteristics on productivity is significant/ detectible when using large datasets retrieved from the StanForD stem files. To do this, a research team could film a variety of harvesters as they worked and model productivity based off the stem files for the full dataset, versus for the dataset with particular cycles (anomalies) removed, and test if these differed significantly.

\section{Conclusions}

The objectives as outlined in the introduction of this study have been achieved. The difference in mean Time Study productivity and mean Stem File productivity was $2.01 \mathrm{~m}^{3} \mathrm{PMH}^{-1}$ for Swath I, 0.53 for Swath II, 0.8 for swath III, and 0.59 for Swath IV (Table 4). In all cases, estimations of productivity were higher when using the Time Study method although this difference was not significant. A relationship between the Time Study productivity and the Stem File productivity is given by Equation 3 . This relationship additionally shows that over the range of productivities experienced in this 
study, the productivity estimate was higher when using manual time study methods. This suggests that there may have been some delay time recorded by the harvester and included in the Stem File data set that was not accounted for and included in the Time Study data set. Productivity models were developed from the Time Study data and from the Stem File data for each swath by plotting individual tree volumes against productivity. No significant differences between productivity models were observed in the four studies completed, once tree volume estimates had been standardized.

\section{Acknowledgements}

The research team would like to thank to York Timbers for providing the study area and data from the study, without their contributions this would not have been possible from the start. We also thank to John Rabie at York Timbers for facilitating the study site, the harvesters and operators for the study, and for assistance with study layout and data collection. Acknowledgements to Helin Dura, Rachel Green, Cody Lai, and Jacques Malan for their assistance in making this study possible.

\section{References}

Ackerman P., Gleasure E., Ackerman S., Shuttleworth B., 2014. Standards for Time Studies for the South African Forest Industry. Web: http://www.forestproductivity. co.za/?page id=678. Accessed August 2, 2017.

Ackerman P., Pulkki R., 2012. Fibre losses of eight softwood clearfell harvesting systems in South Africa. Southern Forests 74(2): 133-149. DOI: 10.2989/20702620.2012.701412

Ackerman P., Williams C., Ackerman S., Nati C., 2017. Diesel consumption and carbon balance in south african pine clear-felling ctl operations: a preliminary case study. Croatian Journal of Forest Engineering 38(1): 65-72.

Ackerman S.A., Seifert, S., Ackerman, P.A., Seifert, T. 2016. Mechanised pine thinning harvesting simulation: productivity and cost improvements as a result of changes in planting geometry. Croatian Journal of Forest Engineering 37(1): 1-15.

Ackerman S.A., Ackerman P.A, Seifert T., 2013. Effects of irregular stand structure on tree growth, crown extension and branchiness of plantation-grown Pinus patula. Southern Forests. 75(4): 247-256. DOI: $10.2989 / 20702620.2013 .846722$

Alam M., Brown M., Strandgard M., Fox, J., 2012. Improving the productivity of mechanised harvesting systems using remote sensing. Australian Forestry 75: 238-245. DOI: 10.1080/00049158.2012.10676408

Arlinger J., Moller J., 2007. Information exchange with CTL machines, recent development of StanForD - a communication standard. 3rd Forest Engineering Conference. Skogforsk, The Forestry Research Institute of Sweden. Mont-Tremblant, Quebec, Canada.

Björheden R., Thompson MA., 1995. An International Nomenclature for Forest Work Study. In DB Field (Ed.), Proceedings of IUFRO 1995 S3:04 subject area: 20th World Congress. IUFRO, Tampere, Finland, pp. 190215.

Bredenkamp V., Upfold S., 2012. South African Forestry Handbook: 5th Edition. Melno Park, Pretoria: South African Institute for Forestry (SAIF).

Brink MP., Malan FS., Kassier HW., 2000. Forest Engineering in Timber plantations: Log definitions and specifications. In Owen D.L. (ed.), South African Forestry Handbook 1: 301-340.

Contreras M., Freitas R., Ribeiro L., Stringer J., Clark C., 2017. Multi-camera surveillance systems for time and motion studies of timber harvesting equipment. Elsevier 135: 208-215.

Cosola G., Grigolato S., Ackerman P., Monterotti S., Cavalli R., 2016. Carbon footprint of forest operations under different management regimes. Croatain Journal of Forest Engineering 37(1): 201-217.

Eliasson L., Bengtsson J., Cedergren J., Lageson H., 1999. Comparison of single-grip harvester productivity in clear and shelterwood cutting. Journal of Forest Engineering 10: 43-48.

Erasmus D., 1994. National Terrain Classification System for Forestry: Version 1.0. Institute for Commercial Forestry Research. ICFR, Pietermaritzburg, South Africa.

Eriksson M., Lindroos O., 2014. Productivity of harvesters and forwarders in CTL operations in northern Sweden based on large follow-up datasets. International Journal of Forest Engineering 25: 179-200. DOI: 10.1080/14942119.2014.974309

Heinemann H., 2001. Productivity of a cut-to-length harvester family - an analysis based on operation data. Proceedings from the 2001 Council on Forest Engineering (COFE): "Appalachian Hardwoods: Managing Change"; July 15-18; Snowshoe, West Virginia.

Holopainen M., Vastaranta M., Rasinmaki J., Kalliovirta J., Makinen A., Haapanen R., Hyyppa J., 2010. Uncertainty in timber assortment estimates predicted from forest inventory. European Journal of Forest Resources 129: 1131-1142. DOI: $10.1007 / \mathrm{s} 10342-010-0401-4$

Jirousek R., Klvak R., Skoupy A., 2007. Productivity and costs of the mechanised cut-to-length wood harvesting system in clear-felling operations. Journal of Forest Science 53: 476-482. DOI: $10.17221 / 2088-J F S$

Kanawaty G (Ed.)., 1992. Introduction to Work Study (4th Edn.). Geneva: International Labour Organisation. 
Kärhä K., Rönkkö E., Gumse S., 2004. Productivity and cutting costs of thinning harvesters. International Journal of Forest Engineering 15: 43-56.

Koskela L., Nummi T., Wenzel S., Kivinen V., 2011. On the analysis of cubic smoothing spline-based stem curve prediction for forest harvesters. Canadian Journal of Forest Research 36: 2909-2920. DOI: 10.1139/ x06-165

Kulak D., Stanczykiewicz A., Szewczyk G., 2017. Productivity and time consumption of timber extraction with a grapple sikidder in selected pine stands. Croatian Journal of Forest Engineering 38: 55-63.

Labelle E., Soucy M., Cry A., Pelletier G., 2016. Effect of tree form on the productivity of a cut-to-length harvester in a hardwood dominated stand. Croatian Journal of Forest Engineering 37: 175-183.

Louw J., Scholes M., 2002. The influence of site factors on nitrogen mineralization in forest soils of the Mpumalanga escarpment area: South Africa. South African Forestry Journal 193: 47-63. DOI: 10.1080/20702620.2002.10433518

Magagnotti N., Kanzian C., Schulmeyer F., Spinelli R., 2011. A new guide for work studies in forestry. International Journal of Forest Engineering 24: 249-253. DOI: 10.1080/14942119.2013.856613

Magagnotti N., Pari L., Spinelli R., 2017. Use, utilization, productivity and fuel consumption of purpose-built and excavator-base harvesters and processors in Italy. Forests 8: 485. DOI: 10.3390/f8120485

Magagnotti N., Spinelli R. (eds.)., 2012. Good practice guidelines for biomass production studies. COST Action FP-0902 and CNR IVALSA, Sesto Fiorentino, Italy. Web: http://www.forestenergy.org/pages/cost-action-fp0902/good-practice-guidelines/.

Nurminen T., Korpunen H., Uusitalo J., 2006. Time Consumption Analysis of the Mechanised Cut-to-length Harvesting System. Silva Fennica 40: 335-363. DOI: 10.14214/sf.346

Nuutinen Y., Vaatainen K., Heinonen J., Roser D., Asikainen J., 2008. The Accuracy of Manually Recorded time Study Data for Harvester Operation Shown via Simulator Screen. Silva Fennica 42: 63-72. DOI: 10.14214/ sf.264

Nuutinen Y., 2013. Possibilities to use automatic and manual timing in time studies on harvester operations. Thesis dissertation, University of Eastern Finland.

Odhiambo B., 2010. The use of time study, method study and GPS tracking in improving operational harvest planning in terms of system productivity and costs. MSc Thesis, Department of Forestry and Wood Science, Stellenbosch University, Stellenbosch.

Olivera A., Visser R., Acuna M., Morgenroth J., 2016. Automatic GNSS-enabled harvester data collection as a tool to evaluate factors affecting harvester productivity in a Eucalyptus spp. harvesting operation in Uruguay. International Journal of Forest Engineering 27: 15-28.

DOI: 10.1080/14942119.2015.1099775

Palander T., Nuutinen Y., Kariniemi A., Väätäinen K., 2013. Automatic Time Study Method for Recording Work Phase Times of Timber Harvesting. Forest Science. 59: 472-483. DOI: 10.5849/forsci.12-009
Ponsse Oyj, 2017. Ponsse Opti information systems wood procurement system [online]. Ponsse Oyj, Vierema, Finland. Web: http://www.ponsse.com/products/ information-systems/wood-procurement. Accessed: November 13, 2017.

Purfürst FT., 2010. Learning curves of harvester operators. Croatian Journal of Forest Engineering 31: 89-97.

Purfürst FT., Lindroos O., 2011. The correlation between long-term productivity and short-term performance ratings of harvester operators. Croatian Journal of Forest Engineering 32: 509.

R Core Team, 2013. R: A language and environment for statistical computing. Vienna, Austria, R Foundation for Statistical Computing.

Ramantswana M., McEwan A., Pauw J., 2012. Determining the effect of tree size, bark-wood bond strength and tree form on the productivity of an excavator-based harvester in Acacia mearnsii in the KwaZulu-Natal forestry region of South Africa. Southern Forests: a Journal of Forest Science 74: 151-157. DOI: 10.2989/20702620.2012.722823

Ross T., du Toit B., Dovey S., 2005. Nutrient pools in slash loads in Pinus patula sawtimber and pulpwood stands in South Africa. Institute for Commercial Forestry Research, Pietermaritzburg, South Africa.

Sängstuvall L., 2010. Estimates of the productivity of logging operations with a focus on forest fuel extraction. Arbetsrapport 297, Skoglig resurshushållning, Sveriges lantbruks universitet, Institutionen for skoglig resurshusha Ilning.

Spinelli R., Laina-Relano R., Magagnotti N., Tolosana E., 2013. Determining observer and method effects on the accuracy of elemental time studies in forest operations. Baltic Forestry 19 (2): 301-306.

Spinelli, R., Lombardini, C., Magagnotti, N., 2014. The effect of mechanization level and harvesting system on the thinning cost of Mediterranean softwood plantations. Silva Fennica 48(1): 1-15. DOI: 10.14214/ sf. 1003

StanForD team, 2007. Standard for Forest Data and communications - main document. Web: https://www.skogforsk.se/english/projects/stanford/stanford-classic-documents/. Accessed: November 13, 2017.

StanForD team, 2012. StanForD listing of variables by category. Version 2012-04-18. Web: https://www.skogforsk.se/english/projects/stanford/stanford-classic-documents/. Accessed: November 13, 2017.

Strandgard M., Walsh D., Acuna M., 2013. Estimating harvester productivity in Pinus radiata plantations using StanForD stem files. Scandinavian Journal of Forest Research 28: 73-80. DOI: 10.1080/02827581.2012.706633

Visser R., Spinelli R., 2012. Determining the shape of the productivity function for mechanized felling and felling-processing. Journal of Forest Research 17: 397402. DOI: $10.1007 / \mathrm{s} 10310-011-0313-2$

Williams C., Ackerman P., 2016. Cost-productivity analysis of South African pine sawtimber mechanised cut-to-length harvesting, Southern Forests: a Journal of Forest Science 78: 267-274. DOI: $10.2989 / 20702620.2016 .1183096$ 